\title{
A Report on XXVII Annual Conference of Indian Association for Angiosperm Taxonomy (IAAT) and International Symposium on Plant Systematics: Priorities and Challenges
}

The XXVII Annual Conference of Indian Association for Angiosperm Taxonomy (IAAT) and International Symposium on "Plant Systematics: Priorities and Challenges" was organized from 10 to 12 November, 2017 at the Department of Botany, University of Delhi, Delhi. The inaugural function was presided over by the Chief Guest, Prof. J.P. Khurana, Pro-ViceChancellor, University of Delhi. Prof. K.S. Rao, Head, Department of Botany, University of Delhi, welcomed the dignitaries and participants. Prof. M. Sabu, Secretary, IAAT highlighted the objectives and functioning of IAAT. Prof. S.V.S. Chauhan, President, IAAT in his address focused on the importance of taxonomic studies for the conservation of biodiversity. Prof. Karol Marhold, Secretary-General, International Association of Plant Taxonomy (IAPT), who was the Guest of honour, emphasized the role of IAPT in promoting systematic studies. Prof. J.P. Khurana released souvenir-cum-abstract and delivered the inaugural address. He threw light on the recent trends in plant systematics and emphasized the need for more focused study on molecular taxonomy and phylogeny of different groups of plants. Dr. K.G. Bhat and Dr. R.V. Gurav were felicitated by the Hon'ble Chief Guest for completing 70 years of age and for organising XXVI IAAT Annual Conference and International Seminar, respectively. Prof. Arun K. Pandey, Organising Secretary proposed the vote of thanks.

Presidential address on "Bignoniaceae in India" was delivered by Prof. S.V.S. Chauhan. Prof. Karol Marhold delivered the Keynote Address on the topic "Genome-wide differentiation of diploid lineages in the emerging plant model Arabidopsis arenosa and infraspecific genetic patterns within related A. halleri". Prof. Sobhan K. Mukherjee (University of Kalyani) delivered Prof. Y.D. Tiagi Gold Medal lecture on the topic "Diversity of micromorphological and histological features of cypselas of Compositae and their taxonomic significance". Prof. V.V. Sivarajan Gold Medal lecture was delivered by Prof. M.M. Sardesai (Savitribai Phule Pune University) on the topic "Floristics: a never ending process". Invited lectures were given by Dr. Kanchi N. Gandhi (Harvard University, USA), Prof. Magnus Liden (Uppsala University, Sweden), Prof. Masoud Sheidaei (Shahid Beheshti University, Iran), Prof. S.R. Yadav (Shivaji University, Kolhapur), Prof. A.P. Das (Rajiv Gandhi University, Itanagar), Prof. T. Pullaiah (Hyderabad), Dr. M. Keshavarzi (Alzahra University, Iran), Prof. S. Rama Rao (North-Eastern Hill University, Shillong) and Prof. C. Habibur Rahaman (Visva-Bharati, Santiniketan).

The themes of the symposium include: 1. Systematics and Evolution of Flowering Plants; 2. Assessment and Conservation of Plant Diversity; 3. Ethnobotany and Bioprospecting; 4. Medicinal and Aromatic Plants; 5. Biogeography, 6. Endemism and Threatened Plants and 7. Impact of Climate Change on Biodiversity.

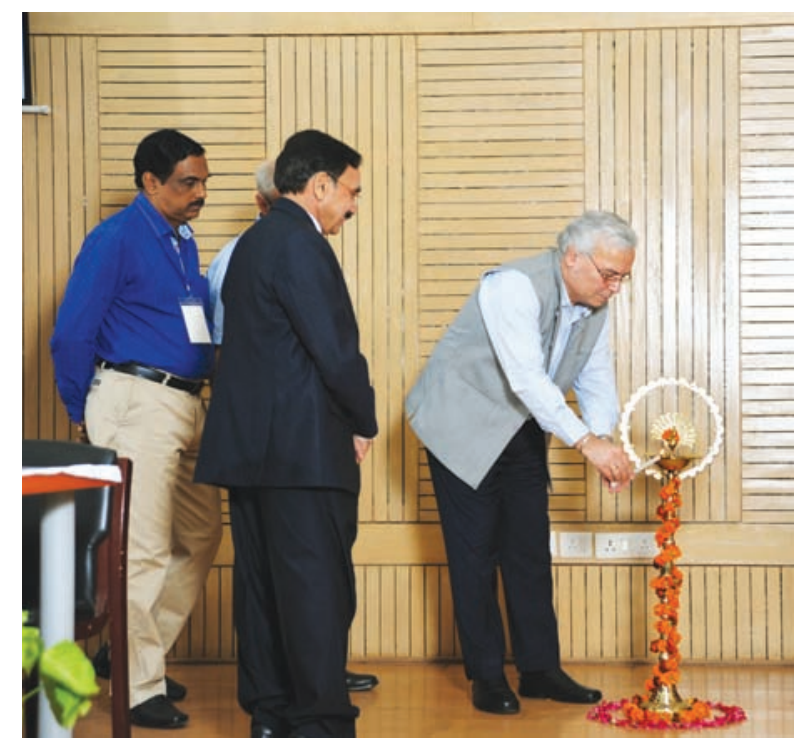

Lighting of the lamp during the inaugural ceremony by Prof. J.P. Khurana, Pro-Vice-Chancellor, University of Delhi. 


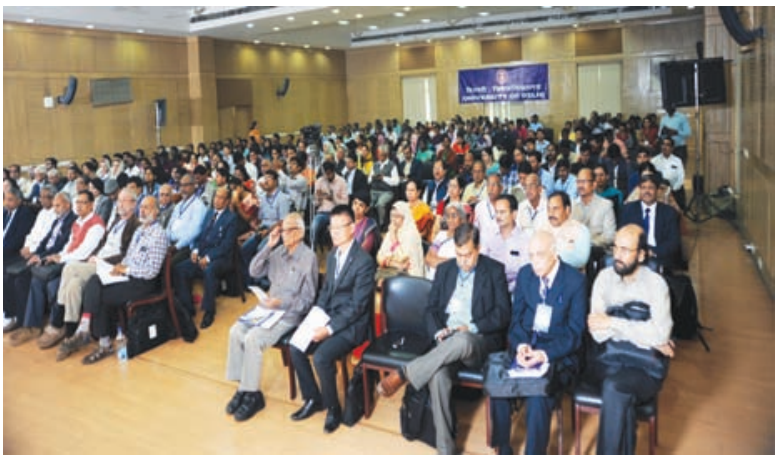

Invited speakers and delegates of IAAT Conference and International Symposium

A Panel Discussion on how to facilitate the biodiversity related research work in conformity with the Biological Diversity Act (2002) was held on the second day of the conference. Drs. M. Sanjappa, R.R. Rao, A.P. Das, A.G. Pandurangan, D. Narasimhan, A.A. Mao, and G.H. Dar participated in the discussion. Issues and problems faced by the taxonomists for plant collections and exchange of
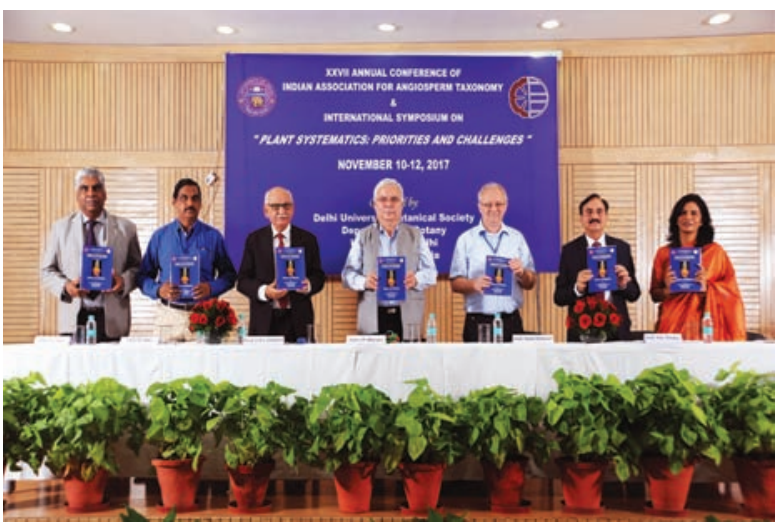

Release of the Souvenir-cum-Abstract of the Conference by the dignitaries on the dais.

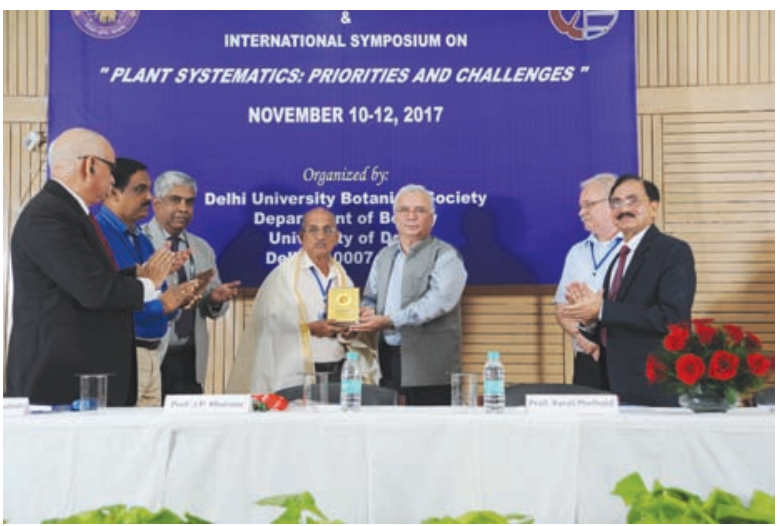

Prof. J.P. Khurana honouring Dr. K.G. Bhat, one of the senior members of IAAT.

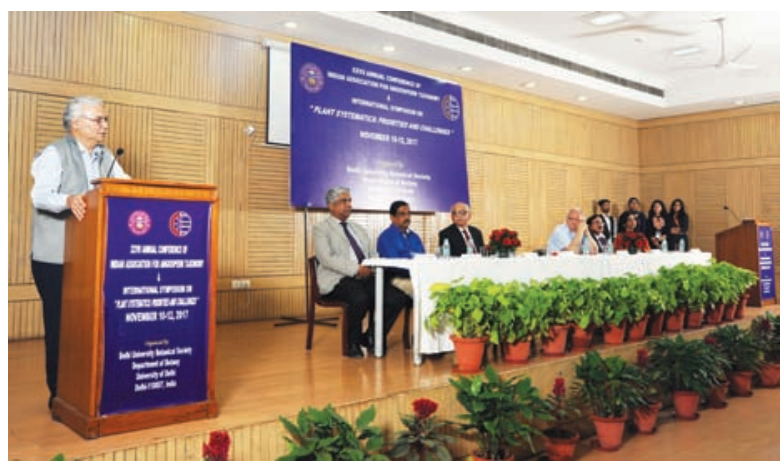

Address by the Chief Guest Prof. J.P. Khurana, Pro-ViceChancellor, University of Delhi.

specimens for research purpose were discussed. It was made clear to the participants that the exchange of specimens is now facilitated through a quick process by applying in "Form B" of National Biodiversity Authority (NBA), whereas obtaining permission is under the purview of respective forest department of a state. A subcommittee was constituted to frame thenecessary recommendations

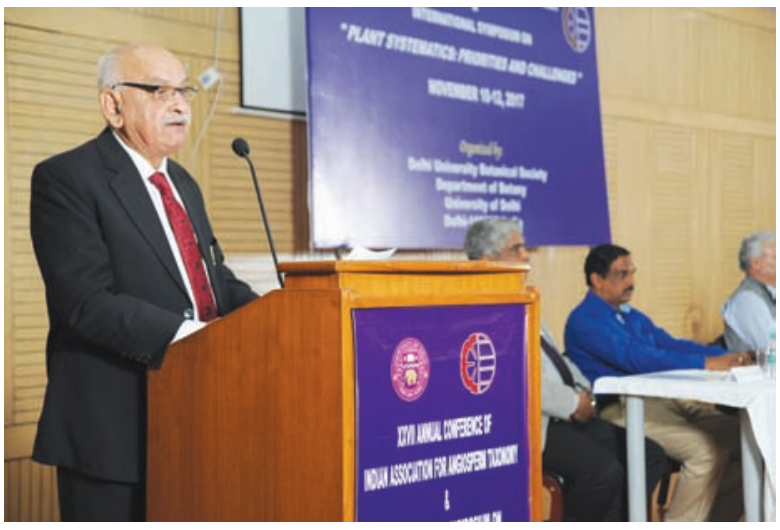

Presidential Address by Prof. S.V.S. Chauhan, President, IAAT.

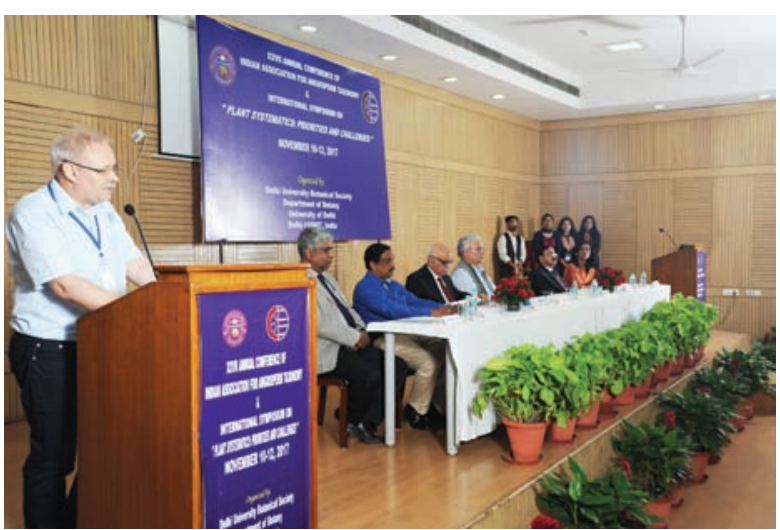

Prof. Karol Marhold, Secretary-General, IAPT, delivering the Keynote Address. 


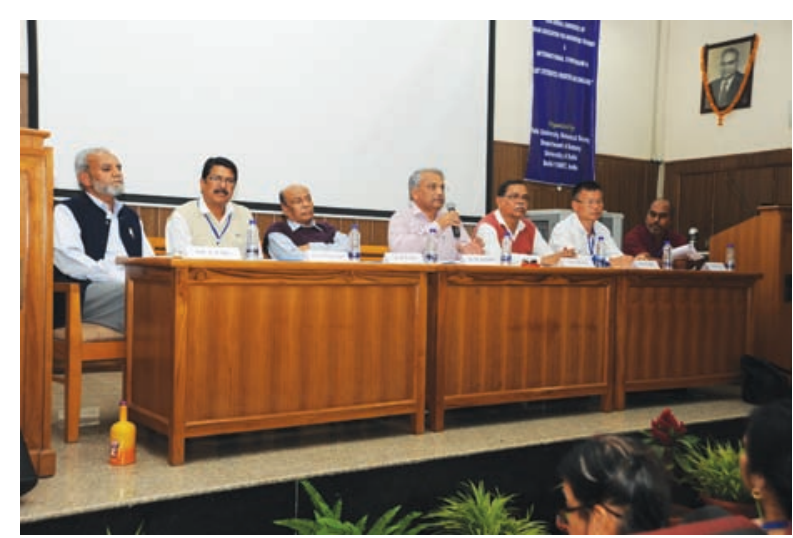

Panel Discussion on Biological Diversity Act 2002.

to be sent to National Biodiversity Authority and National Wildlife Board, for facilitating taxonomic research.

A total of 385 delegates from across the country and from abroad participated. Oral and poster research papers totalling 200 were presented during the conference in four parallel sessions. The following awards were given to the best presenters selected by a panel of judges for each theme.

1. K.S. Manilal Award for best paper in Floristics (New Species/New Reports): S.K. Gawade, Shivaji University, Kolhapur.

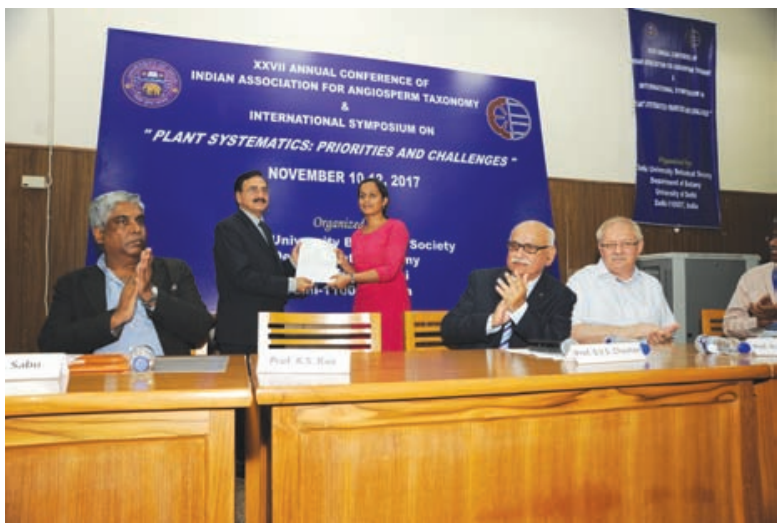

Prof. A.K. Pandey giving Fr. Anthony Mukkath-K.S. Manilal Award to Ms. K. Smitha.

2. Rolla S. Rao Award for best paper in Biodiversity Conservation: Ms. Prabha M. Pillai, Goa University, Goa.

3. T.R. Sahu Award for best paper in Medicinal Plant Systematics: Mr. Anindya Sunder Ray, Visva-Bharati University, Santiniketan.

4. S.R. Yadav Award for best poster presentation: Ms. Resmi, University of Calicut, Calicut.

5. Fr. Antony Mukkath-K.S. Manilal Award for best paper in Modern Techniques in Plant Taxonomy: Ms. K. Smitha, University of Calicut, Calicut.

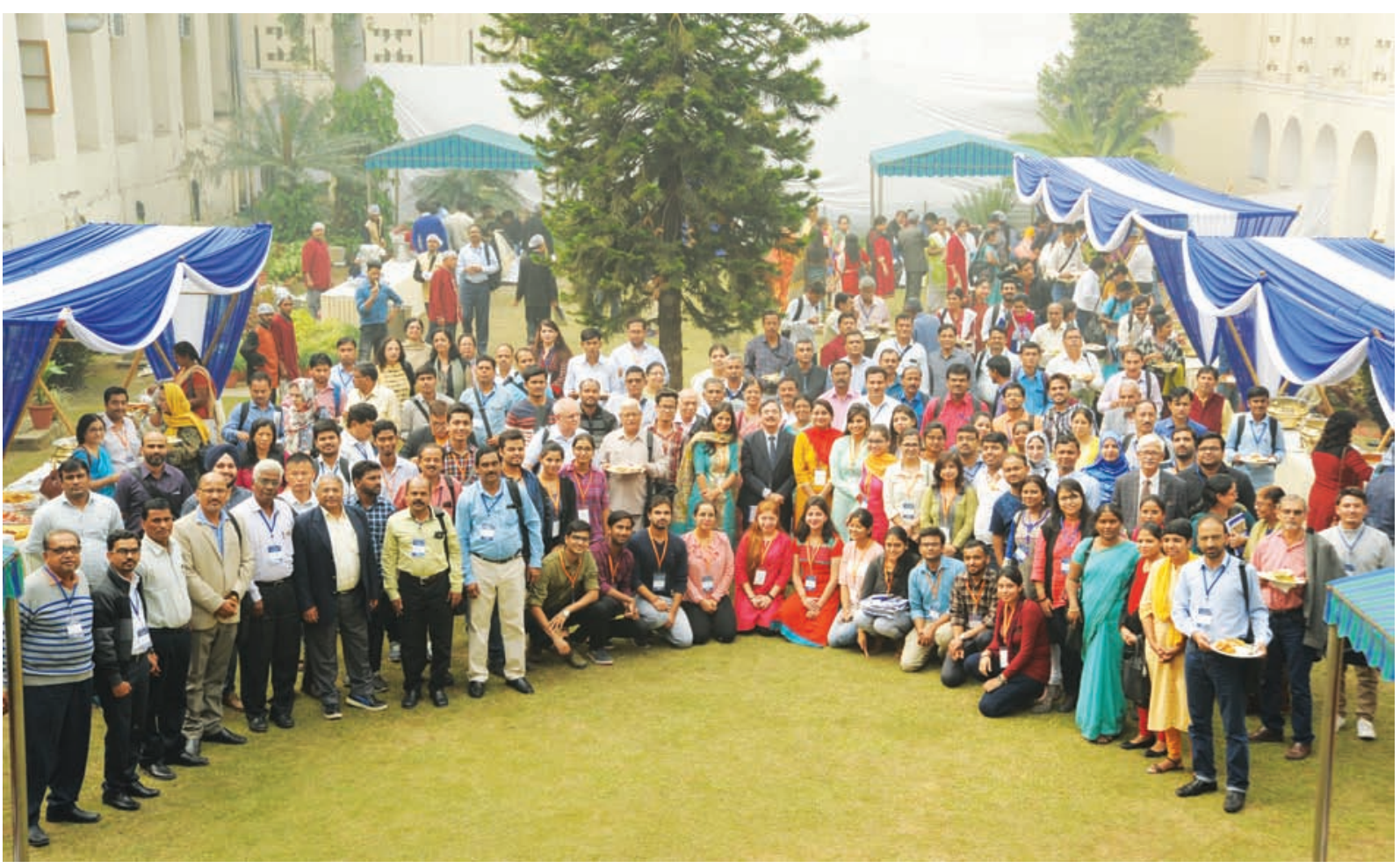

Participants of the IAAT Conference and International Symposium. 
6. Prof. M. Sabu Award for best paper in Angiosperm Taxonomy (for Teachers and Scientists): Dr. Sharad S. Kamble, MVP's Arts, Science and Commerce College, Nashik.

The Executive Committee (EC) meeting of IAAT was held at the Department of Botany, University of Delhi on November 10, 2017 followed by General Body (GB) meeting on November 11, 2017. General Body approved the decision taken at the EC meeting to do away with the printed copies of Rheedea for sending to the life members due to the financial constraints in printing and posting the Journal. However, it was decided in the GB meeting to print the necessary number of copies for exchange and library subscriptions.

A street play on Natural Selection was performed by the students of the Department of Botany, University of Delhi on the evening of November 11, 2017. This Conference was sponsored by the
National Biodiversity Authority, Science and Engineering Research Board (SERB) and the University of Delhi.

The participants unanimously acknowledged and appreciated the excellent and efficient organization of the conference. Prof. M. Sabu announced winners for the six awards which were distributed by the dignitaries on the dais. In his valedictory remarks, Prof. S.V.S. Chauhan suggested that there should be integration of modern tools and methods for study, sustainable use and conservation of plant diversity in India. Prof. Arun K. Pandey, Organizing Secretary of the Conference proposed the vote of thanks.
Arun K. Pandey

Department of Botany University of Delhi, Delhi - 110007 